resources for alcohol rehabilitation programmes for drink driving offenders and publicity about the dangers of drink driving at all times of the year, not only at Christmas.

We are most concerned with local action. We have devised a "Coventry says no to drink driving" logo and are approaching local groups that should be able to help-for example, taxi firms, insurance companies, and soft drinks manufacturers. We want motor manufacturers and dealers to distribute leaflets on drinking and driving with the cars they sell. The Royal Automobile Club has offered to circulate its members in Coventry with information. We also want publicans and off licences to display the logo (perhaps on beer mats) and supply information. Local landlords will, we hope, participate in a "walk to your local" campaign. Local magistrates may choose to limit the number of new licences that they grant, and the police have a part to play in changing prosecution practices. The local alcohol advisory service and the probation service hope to provide more alcohol rehabilitation for convicted drivers. Unfortunately, the West Midlands Passenger Transport Authority has "rescheduled" late night bus services, making it more difficult for people to drink but not drive. Providing late night transport once again is being considered as one way of preventing drink related accidents and violence.

We have a long way to go to achieve our aim of making Coventry a no drinking and driving city by the year 2000, but we hope that other areas will consider adopting similar schemes. Increased local action to combat drinking and driving might create irresistible pressure for changes in national legislation.

Coventry Safe Driving Team (Terry Rollings, Mike Hoyland, Robert Purser, Jean Warren,

Health Education Department, John Middleton, George Pollock)

Coventry Health Authority,

Christchurch House,

Greyfriars Lane,

Coventry CV1 2GQ

\section{Surgery of morbid obesity}

The Americans call the surgery of morbid obesity bariatric surgery, and it has evolved rapidly because of the failure of dietary treatment to control massive obesity. About 34 million Americans aged 20 to 75 are overweight, and no fewer than 12.4 million are severely overweight. The numbers are increasing, particularly among the black population and those in the lower socioeconomic classes. ${ }^{1}$ Severe obesitythat is, a body mass index (weight divided by height squared) over 35-is associated with a higher mortality. Those with a body mass index over 40 find it hard to obtain normal employment or to get life insurance, and with such obesity weight loss by dietary restriction is extremely difficult. It requires rigorous energy restriction for more than a year and for this reason is rarely successful. Radical solutions have thus been proposed, the simplest of which is dental splinting. It is successful in producing weight loss, but once the splint is removed few patients manage to maintain their lower weight.

Bariatric surgery achieves weight loss by restricting food intake and in some operations by causing fat malabsorption. Two main methods have been developed in the past 20 years-gastric and intestinal bypass surgery. These operations also make it more difficult to regain the lost weight by preventing overeating. Intestinal bypass, which was extremely popular during the 1970 s, was achieved by excluding varying lengths of the small intestine and sometimes anastamosing the blind loop to the gall bladder. Gastric bypass has developed from a classic gastrointestinal bypass based on a Bilroth II operation to varying forms of gastric partition that reduce the gastric channel to the duodenum.

A sequential study from 1972 to 1982 suggested that reasonable weight loss occurred with all the operations. ${ }^{2}$ A 13 year review of jejunoileal bypass on 180 patients in one unit showed that this procedure was a most effective operation for morbid obesity and that with experience it could be performed safely. ${ }^{3}$ Unfortunately, the complication rate and difficulty of maintaining satisfactory follow up on many young patients made it unacceptable for performing on a large scale, although it is easily done and can be reversed without difficulty. Gastric bypass was associated with far fewer serious long term complications but was difficult to reverse.

Various forms of gastric bypass have been described in the past five years, but the present most favoured method is the vertical banding gastroplasty devised by Mason. ${ }^{4}$ Several reports have cited failure to lose weight after gastroplasty and described corrective operations, but more worrying is the failure to report complications. There are, compared with jejunoileal bypass, few long term studies in depth of gastroplasty. Thus a report of gastritis and gastric dysplasia in four fifths of 28 patients who had undergone an Alden modification of the gastric bypass procedure between 1979 and 1981 is important..$^{5}$ In this operation the stomach is cross stapled and an anticolic loop gastroenterostomy is performed with a 30 $\mathrm{ml}$ upper gastric pouch. Gastric dysplasia is of great concern and careful follow up becomes imperative, as it is after gastric surgery for peptic ulceration because of the increased incidence of cancer.

No single surgical procedure will be satisfactory in every case and none can be applied by the occasional practitioner. What is the alternative? Bjorvell and Rössner have reported a four year programme of treatment combining standard techniques such as behavioural modifications, nutritional advice, and readmission on relapse with surgical treatment. ${ }^{6}$ One third of their patients had their jaws wired, and of the 107 entered into the trial no less than one third had left the programme after four years. The mean loss of weight was $11.7 \mathrm{~kg}$ or $27 \%$ of the excess weight before treatment. Those who had their jaws fixed lost more weight than those treated medically; but they regained more weight. As in many other trials, patient motivation was poor.

When results are so poor should surgery for morbid obesity be reserved for those in danger of dying? Can such a group be defined? Should body image be a criterion for surgery, or should surgery be advocated for those with appreciable hypertension, maturity onset diabetes, or hyperlipidaemia? Now that bariatric surgery is here to stay, we must examine the achievements before attacking new goals; certainly, we need long term trials. Meanwhile, in our unit we are resting.

J-C GAZET Consultant surgeon

T R E PILKINGTON Professor of medicine

St George's Hospital and Medical School, London SW17 ORE 
1 Raymond CA. Biology, culture, and dietary changes conspire to increase incidence of obesity IAMA 1986;256:2157-85.

Haffner JFW, Lande G, Bergan A, Fausa O, Nygard K. Gastric and jejunoileal bypass. A retrospective comparison. Clinical Nutrition 1986;6:97-100.

McFarland RJ, Gazet J-C, Pilkington TRE. A 13-year review of jejunoileal bypass. $\mathrm{Br} \mathcal{J}$ Surg 1985;72:81-7.

Mason EE, ed. Development of operations in surgical treatment for obesity. London: Saunders, 1981:1-60.

McCarthy HB, Rucker RD, Chan EK, et al. Gastritis after gastric bypass surgery. Surgery 1985;98:68-71.

6 Bjorvell H, Rössner S. Long term treatment of severe obesity: four year follow-up of results of combined behavioural modification programme. BrMed f 1985;291:379-82.

\section{A shocking American report with lessons for all}

A remarkable and chilling report from a subcommittee of the United States House of Representatives detailed many experiments in which people were exposed to potentially toxic doses of radioactivity simply to satisfy scientific curiosity. ${ }^{1}$ The people had no hope of benefiting themselves. In some cases they had given "informed consent," although it is doubtful that they had been well informed about the dangers of radiation. Those who were not asked to consent were prisoners or hospital patients including the mentally and terminally ill. The experiments took place between 1945 and 1971; the early experiments might be excused by the ignorance of the long term effects of radiation, or explained by the atomic hubris that followed the bombing of Hiroshima, but some of the later experiments took place when the dangers were only too well known.

Some examples will give the flavour of the report. Between 1961 and 1965 at the Massachusetts Institute of Technology 20 elderly volunteers from the nearby New England Age Center were injected with radium or thorium to examine the metabolism of these substances. The subjects had volunteered to take part in experiments studying the aging process but not a study such as that done. There was no benefit to the volunteers and no long term follow up.

From 1945 to 1947,18 hospital patients with a short expectation of life were injected with plutonium to measure the quantity retained in the body. The subjects received between 1.6 and 98 times the permissible occupational dose at that time. One of the subjects was 5 years old. There was no informed consent, and many of the original diagnoses were inaccurate; seven of the patients lived for more than 10 years, four for more than 25 years, and one was alive 36 years after the experiment. The injections were represented as experimental treatments for the patients' illnesses-a statement that was palpably dishonest.

Between 1963 and 1971 over 100 inmates of Washington and Oregon state prisons were subjected to testicular irradiation to determine a dose that would sterilise them. The projects were funded by the Atomic Energy Commission to the tune of $\$ 1.5 \mathrm{~m}$. There was no long term follow up to guard against the risk of testicular tumours.

During 1946 and 1947 six patients with good renal function were injected with increasing doses of uranium-234 and uranium-235 to determine the dose necessary to produce renal injury. The patients were mainly chronic alcoholics, homeless, and emotionally disturbed - and one was having hallucinations. The carrot for taking part was a warm bed in hospital.

It is unnecessary to go on. Undoubtedly in these experi- ments ethical standards were flouted in a manner that is almost beyond belief. The one redeeming feature is that the United States is an open society and therefore this information has become available. In many other countries it would remain an official secret.

Doctors everywhere will condemn this disregard of human rights, but these experiments are an extreme extension of the phase 1 trial in which potential drugs are given in man for the first time. Any agent intended for human use should be fully evaluated in the test tube and in laboratory animals before being used in man, but interspecies variation ensures that not all possible hazards will be predicted. Trials in healthy subjects must always be ethically dubious and are a breach of human rights if participants are not fully informed or are coerced into taking part. Thus prisoners, inmates of mental institutions, and employees of the firm or institution doing the experiments are not suitable subjects. The Helsinki Declaration of the World Medical Association states that the physician may justify experimentation on humans only if it has a therapeutic value in terms of the subject. ${ }^{2}$ Some people might willingly forgo their rights as an altruistic act, but studies in which the person runs a risk but will not benefit need to be governed by the strictest ethical criteria. ${ }^{3}$

Experiments within medical establishments are already covered by comprehensive guidelines. ${ }^{4}$ What this congressional report achieves is to shock us into regulating human experimentation in non-medical, academic, industrial, and military environments.

Professor of Haematology,

T J HAMBLIN

Royal Victoria Hospital,

Bournemouth BH1 4JG

1 US House of Representatives Subcommittee. American nuclear guinea pigs: three decades of radiation experiments on US citizens. Washington, DC: Committee on Energy and Commerce, US House of Representatives, 1986. (Subcommittee staff report for the Subcommittee on Energy ConservaRepresentatives, 1986. (Subcommittee staff report for the Subco tion and Power of the Committee on Energy and Commerce.)

2 World Medical Association. Human experimentation. Code of ethics of the World Medical Association. Declaration of Helsinki. BrMed $\mathcal{F} 1964 ;$;i: 173.

3 Durry G, Dion S. The ethical approach to phase 1 clinical trials in oncology. In: Mathe G, Reizenstein $\mathrm{P}$, Dicato M, eds. Clinical trials in oncology: ethics, enrors, methods and results. Geneva: Bioscience Ediprint, 1986:21-2.

4 Royal College of Physicians. Guidelines on the practice of ethical committees in medical research. London: Royal College of Physicians, 1984.

\section{AIDS: a faltering step}

Last week the annual representative meeting of the BMA passed by 183 to 140 votes a motion saying that doctors should be allowed to test a patient for antibodies to the human immunodeficiency virus (HIV) without first gaining consent ( $p$ 148). The debate was largely concerned with what the proposer called "occasional circumstances," but the motion did not contain that phrase and nor did most of the reports in the media. The BMA thus appears to have departed from the advice given by both the World Health Organisation and the Department of Health and Social Security, and, in our view, the decision might do serious damage to Britain's attempt to contain the epidemic of the acquired immune deficiency syndrome (AIDS).

So far Britain has done reasonably well in its struggle to contain the disease. In particular we have resisted the tendency seen in some countries to victimise those in risk groups and to use draconian measures in what will certainly 